\title{
Femoroasetabular sıkışma (FAS) sendromu - tarihçe, tanımlama ve doğal seyir
}

\author{
Femoracetabular impingement (FAI) syndrome - definition and natural history
}

\author{
Cemalettin Aksoy \\ Hacettepe Üniversitesi Tıp Fakültesi Ortopedi ve Travmatoloji Anabilim Dalı, Ankara
}

\begin{abstract}
Femoroasetabular sıkışma sendromu, günümüzde erken kalça osteoartritinin önemli ve önlenebilir nedenleri arasında sayılmaktadır. Hastalığın toplum içinde sıklığının bilinmemesi, şikayeti olmayan, ancak morfolojik bulguların bulunan bireylerde doğal seyrinin tanımlanmamış ve tedavisi konusundaki çekincelerin tam olarak giderilmemiş olması, bu sorunu halen tartışılır durumda tutmaktadır. Hastalık, genç erişkinlerde önemli kalça ağrısı nedenleri arasında yer alır ve tartışılan tüm özelliklerine rağmen, önemli bir grup hastada tedavi edilebilir.
\end{abstract}

Anahtar sözcükler: femoroasetabular sıkışma; kalça ağrısı; erken osteoartrit
Femoracetabular impingement is one of most important and preventable precursor of early hip osteoarthritis. The incidence of the disease is not clearly known in the population. We also do not know the natural history of the people who have morphological changes of acetabulofemoral impingement. The treatment indications are open for discussion due to lack of knowledge. The disease is still one of the most important reason of hip pain and treatable situation in symptomatic patients although there are to many conflicts. Further studies are necessary to evaluate natural history of the disease and effectiveness of treatment.

Key words: femoroacetabular impingement; hip pain; early osteoarthritis emoroasetabular sıkışma (FAS) sendromu, 2003 yılında Ganz ve arkadaşları tarafından tanımlandıktan sonra, günümüze kadar sürekli tartışılan bir konu olarak ortopedi alanında yer almıştır. ${ }^{[1]}$ Tanımlanmasından sonra, öncelikli olarak açık cerrahi dislokasyonla tedavi edilen hastalık, günümüzde belli oranlarda artroskopik olarak tedavi edilebilir hale gelmiştir. Bu hastalık, tanımlanmasından sonra günümüze kadar geçen tarihsel süreç içerisinde, üzerinde çok sayıda yazı yazılan, bilimsel toplantılarda çok fazla tartışılan konu başlıklarından birisi olmuştur. Ayrıca tedavi endikasyonları, hastalığın doğal seyri ve tedavi yöntemi de hala tam olarak belirlenmiş değildir. Bu durum, hastalığı ilginç kılmakta ve gündemde tutmaktadır. Hastalığı önemli ve tartışılır hale getiren en temel özellikler, doğal seyrinin tam olarak bilinmemesi, bu morfolojik özelliklerin toplum içinde asemptomatik olarak hangi oranda var olduğunun tam olarak belirlenmemiş olması ve tedavinin etkinliği hakkında yeterli uzun dönemli sonuçların olmamasıdır. Ancak, günümüzde gelinen noktada, semptomatik bireylerde FAS varlığı, erken osteoartrit için önemli bir neden olarak kabul edilmektedir.

\section{AMAÇ VE HASTALIĞIN TANIMI}

FAS'ın tanımlanmasındaki temel amaç, hastalığın doğal seyrini değiştirerek, erken osteoartritin engellenmesi ve bu arada gereksiz girişimlerden kaçınılmasıdır. Çünkü, günümüzde gelinen noktada, hastalık daha fazla tanı almakta, daha yoğun biçimde tedavi edilmektedir. Hastalığın adolesan dönemde yapılan aktif spor faaliyetleri ile ilgisi de, araştırılan konular arasında yer almaktadır. ${ }^{[2]}$

FAS'ta meydana gelen temel sorun, femur başı ile asetabulum arasındaki uyumun bozulması ve bozulan eklem uyumu nedeni ile, labral lezyonların ve kıkırdak hasarının ortaya çıkmasıdır. Bu lezyonlar, kalça ağrısı ve hareket kısıtlılığına yol açar. FAS'ta tanım olarak patolojik durum, femur baş-boyun bileşkesinde veya

- İletişim adresi: Prof. Dr. Cemalettin Aksoy, Hacettepe Üniversitesi Tıp Fakültesi Ortopedi ve Travmatoloji Anabilim Dalı, Ankara Tel: 0532 - 2310076 e-posta: dcemaksoy@hotmail.com

- Geliş tarihi: 10 Ocak $2016 \quad$ Kabul tarihi: 10 Ocak 2016 
asetabulumda meydana gelmektedir. Hastaların önemli bir bölümünde sorun, her iki tarafı da ilgilendirmektedir. cam tipi lezyonlarda, femur baş-boyun bileşkesinde var olan çıkıntı, eklem uyumunu bozar. Pincer lezyonlarında, femur başı asetabulum tarafindan aşıı miktarda örtünmüş durumdadır. Her iki lezyonun meydana getirdiği artiküler hasar, farklı biçimler içerir.

Cam lezyonlarında, femur başı küresel niteliğini kaybeder. Baş-boyun bileşkesinde ortaya çıkan hump, femur baş-boyun ofsetinin azalmasına yol açar. Bu çıkıntı, genellikle bileşkenin anterolateral veya anterosuperior bölümünde yer alır. ${ }^{[3]} \mathrm{Bu}$ nedenle, cam lezyonları, genellikle kalça fleksiyona getirildiğinde bulgu verir.

Pincer lezyonlarında, asetabulumda retroversiyon ile birlikte lokalize bir büyüme veya koksa profunda (coxa profunda) ve protrüzyo asetabuli (protrusio asetabuli) gibi tüm asetabulumu ilgilendiren sorunlarla birlikte olabilir. Pincer lezyonlarında, kalça fleksiyona geldiğinde labrum hasarına yol açar. Tekrarlayan mikro-travma nedeni ile, sonuçta labrum asetabular kartilajdan ayrılır. ${ }^{[3]}$

FAS sonucunda labral lezyonun ve kıkırdak hasarının ortaya çıkması, klinik bulguları meydana getirir. Clohisy ve arkadaşları, FAS sendromu nedeni ile cerrahi tedavi edilen hastaların \%93'ünde labral lezyon, \%83'ünde kıkırdak hasarı tespit etmişlerdir. ${ }^{[4]}$ Cam lezyonlarında öncelikle kartilaj hasarı meydana gelirken, pincer lezyonlarında hasar öncelikle labrumda ortaya çıkar. Kombine lezyonlarda, hem kartilaj hem de labral lezyonlar görülür. Doğal olarak, semptomlar başladıktan sonra tedaviye kadar geçen süre uzadıkça, ortaya çıkan hasar artar.

\section{HASTALIĞIN ETKILEDIĞi GRUPLAR}

Hastalık, tedavi yaşı ortalama 28 olmakla birlikte, kadınlarda bir miktar daha sık görülmektedir. ${ }^{[4]}$ Lezyon tiplerine göre bakıldığında, pincer tipi lezyonlar kadınlarda daha sık görülürken, cam tipi lezyonlar erkeklerde daha sık görülmektedir. ${ }^{[4]}$

Çocukluk yaş grubunda görülen hastalıklar da, ileri yaşlarda FAS nedeni olmaktadır. Özellikle, femur başını deforme eden femur üst uç epifiz kayması ve LeggCalvé-Perthes hastalıkları, FAS nedeni olabilir. Femur üst uç epifiz kaymasında, basin kayması ve sonrasında oluşan yeni kemik ve femur başının ortaya çıkan şekli, sıkışma nedeni olabilir. Ayrıca, Legg-Calvé-Perthes hastalığında ortaya çıkan koksa magna (coxa magna) ve baş deformitesi de sıkışma sendromu için uygun ortam hazırlar. Bu hastalıkların günümüzde yapılan tedavi girişimlerinin, uzun dönemde FAS oranları üzerine etkisi tam olarak bilinmemektedir.
Çocukluk yaş grubunda yapılan pelvik cerrahi girişimlerin de FAS oranları üzerine etkisi tam olarak bilinmemektedir. İsteyerek veya istemeden yapılan aşırı örtünme girişimleri de FAS nedeni olabilir; ancak bu durumlarda, çocukluk yaş grubunda var olan yeniden şekillenme potansiyeli de göz ardı edilemez. Bu alan halen araştırmaya açık görülmektedir. Aksoy ve arkadaşları yaptıkları bir çalışmada, Dega asetabuloplasti girişimi sonrasında asetabular indeks değerlerinin büyüme ile artış gösterdiğini ortaya koymuşlardır. ${ }^{[5]} \mathrm{Bu}$ durum, çocukluk yaş grubunda pelvik osteotomi sonrasında asetabular gelişimin devam ettiğini ve yeniden şekillenmenin olanaklı olduğunu ortaya koymaktadır.

FAS morfolojisinin ortaya çıkmasında genetik faktörler ve fiziksel aktivite şekilleri de önemli rol oynayabilir. Pollard ve arkadaşları, sıkışma için genetik faktörlerin önemine vurgu yapmışlardır. ${ }^{[6]}$

Sportif aktivite de FAS için önemli bir etiyolojik faktör olarak görünmektedir. Yüksek temas ve çarpma sporları (futbol, basketbol, hokey) ile uğraşan bireylerde, FAS daha sık olarak görülmektedir. ${ }^{[7]}$ Ayrıca, yapılan bir çalışmada, Agricola ve arkadaşları preprofesyonel adolesan sporcularda, proksimal femur morfolojisinin sıkışma yönünde değiştiğini ortaya koymuşlardır. ${ }^{[8]}$

Sonuç olarak; hastalık, her iki cinsiyeti de etkileyebilen genetik ve çevresel faktörlerle uyarılan bir özellik taşımaktadır. Suprafizyolojik aktivitelerin de hastalık sürecinin gelişimine etkili olduğu görülmektedir.

\section{DOĞAL SEYIR}

FAS doğal seyrinin bilinmesi, tedavi algoritmalarını oluşturmada en önemli parametre olarak karşımızdadır. Ganz ve arkadaşları, cerrahi kalça dislokasyonunda ortaya çıkan morfolojik değişiklikler ve hastalığın seyri içinde ortaya çıkan patolojik durumları göz önüne alarak, FAS'ı, kalça osteoartritinin öncül bir patolojik durumu olarak tanımlamışlar, ${ }^{[1,9]}$ cam lezyonlarının daha fazla osteoartrit riski taşıdığını da ifade etmişlerdir. ${ }^{[9]}$ Bir ileriye dönük kontrollü çalışmada, alfa açısının artışı ile birlikte osteoartrit riskinin giderek arttığı, yani deformitenin şiddetinin osteoartrit oluşumunu tetiklediği gösterilmiştir. ${ }^{[10]}$ Cam lezyonları osteoartritle daha yakından ilişkilendirilmesine rağmen, izole cam lezyonları nadir olarak görülmektedir. Bu nedenle, osteoartrit sürecinin bir bütün olarak değerlendirilmesi daha sağlıklıdır. Bu süreç içinde birçok inflamatuvar patolojik değişiklik meydana gelmektedir.

Doğal seyir tartışmalarında esas değerlendirilmesi gereken grup, FAS morfolojisine sahip, ancak asemptomatik bireylerdir. Cam ve pincer morfolojisi toplumda, sırası ile \%37 ve \%63'e varan oranlarda 
görülmektedir. ${ }^{[11]}$ Bu durum, toplumda birçok bireyin FAS morfolojisine sahip olduğunu gösterir. Bu kadar yüksek oranda görülen morfolojik özellikler dolayısıyla tüm bireylerde hastalık olduğunu iddia etmek olanaklı değildir. Bu nedenle, cam ve pincer deformitelerinin asemptomatik bireylerde osteoartrit ile ilişkisi tam ve doğrudan değildir.

Doğal seyir tartışmalarında değerlendirilmesi gereken diğer konulardan biri de, tedavinin doğal seyir üzerindeki etkisinin belirlenmesidir. Günümüzde, asemptomatik bireylerin tedavisi rasyonel bir yaklaşım olarak görülmemektedir. Ancak, semptomatik hastalarda FAS tedavisi, başarılı ve emniyetli biçimde, açık veya artroskopik olarak gerçekleştirilmektedir. Gerek açık gerekse de artroskopik tedavi girişimleri, benzer oranda orta dönem iyileşmeyi sağlar. Bu hastaların uzun dönemdeki osteoartrit sıklığı ise henüz tam bilinmemektedir.

Sonuç olarak; FAS doğal seyrinin tanımlanması, tedavinin doğal seyir üzerindeki etkisinin ve önemli bir nokta olarak, asemtomatik fakat FAS morfolojisine sahip bireylerin osteoartrit gelişim süreçlerinin ortaya konması için, daha fazla çalışmaya ihtiyaç vardır. Bu noktada, osteoartrit sürecini etkileyen diğer morfolojik ve biyokimyasal süreçlerin açıklanması da, doğal seyir tartışmalarına yön verecektir.

\section{SONUÇ}

FAS, tanımlandığı günden günümüze kadar ortopedi kavramları içinde yoğun biçimde tartışılan konulardan biri olmuştur. Hastalığın gerek tanısı gerek tedavisi hakkında, literatürde çok sayıda yayın mevcuttur. Genel kabul: semtomatik bireylerde bu durum osteoartrit süreci içinde yer almaktadır. Günümüzde açık cerrahi veya artroskopik olarak tedavi edilen bu sendromun etiyopatogenezinin tam aydınlatılması, tedavi yönteminin netleştirilmesi ve idealize edilmesi için, daha birçok çalışmaya ihtiyaç vardır.

\section{KAYNAKLAR}

1. Ganz R, Parvizi J, Leunig M, Nötzli $H$, Siebenrock KA. Femoroacetabular impingement: a cause for osteoarthritis of the hip. Clin Orthop Relat Res 2003;(417):112-20.

2. Siebenrock KA, Ferner F, Noble PC, Santore RF, Werlen S, Mamisch TC. The cam-type deformity of the proximal femur arises in childhood in response to vigorous sporting activity. Clin Orthop Relat Res 2011;469(11):3229-40. Crossref

3. Bedi A, Kelly BT. Femoroacetabular impingement. J Bone Joint Surg Am 2013;95(1):82-92. Crossref

4. Clohisy JC, Baca G, Beaulé PE, Kim YJ, Larson CM, Millis MB, Podeszwa DA, Schoenecker PL, Sierra RJ, Sink EL, Sucato DJ, Trousdale RT, Zaltz I; ANCHOR Study Group. Descriptive epidemiology of femoroacetabular impingement: a North American cohort of patients undergoing surgery. Am J Sports Med 2013;41(6):1348-56. Crossref

5. Aksoy C, Yilgor Ç, Demirkiran G, Çaglar O. Evaluation of acetabular development after Dega acetabuloplasty in devalopmental dysplasia of the hip. J Pediatr Orthop B 2013;22(2):91-5. Crossref

6. Pollard TC, Villar RN, Norton MR, Fern ED, Williams MR, Murray DW, Carr AJ. Genetik influences in the aetiology of femoroacetabular impingement: a sibling study. J Bone Joint Surg Br 2010;92(2):209-16. Crossref

7. Nepple JJ, Vigdorchik JM, Clohisy JC. What Is the Association Between Sports Participation and the Development of Proximal Femoral Cam Deformity? A Systematic Review and Meta-analysis. Am J Sports Med 2015;43(11):2833-40. Crossref

8. Agricola R, Heijboer MP, Ginai AZ, Roels P, Zadpoor AA, Verhaar JA, Weinans $\mathrm{H}$, Waarsing $\mathrm{JH}$. A cam deformity is gradually acquired during skeletal maturation in adolescent and young male soccer players: a prospective study with minimum 2-year follow-up. Am J Sports Med 2014;42(4):798806. Crossref

9. Ganz R, Leunig M, Leunig-Ganz K, Harris WH. The etiology of osteoarthritis of the hip: an integrated mechanical concept. Clin Orthop Relat Res 2008;466(2):264-72. Crossref

10. Agricola R, Heijboer MP, Bierma-Zeinstra SM, Verhaar $\mathrm{JA}$, Weinans $\mathrm{H}$, Waarsing $\mathrm{JH}$. Cam impingement causes osteoarthritis of the hip: a nationwide prospective cohort study (CHECK). Ann Rheum Dis 2013;72(6):918-23. Crossref

11. Frank JM, Harris JD, Erickson BJ, Slikker W 3rd, Bush-Joseph CA, Salata MJ, Nho SJ. Prevalence of Femoroacetabular Impingement Imaging Findings in Asymptomatic Volunteers: A Systematic Review. Arthroscopy 2015;31(6):1199-204. Crossref 